\title{
UN POSIBLE ÉTIMO ÁRABE PARA RUFIÁN
}

\author{
Elena Pezzi
}

El vocablo rufián, también antiguamente rofián, en germanía, designa al chulo que tiene una o varias mujeres prostituyéndose para vivir a cuenta de ellas y que sale en su defensa en los casos en que lo necesitan. Covarrubias lo define: "el que trae mugeres para ganar con ellas, y riñe sus pendencias" y en el Diccionario de Autoridades se dice: "el que trata y vive deshonestamente con mujeres, solicitándolas o consintiéndolas el trato con otros hombres. Llámase así también el que por causas torpes riñe sus pendencias". El verbo rufianar o rufianear tiene el sentido de 'alcahuetear'.

El Diccionario de Autoridades dice de chulo (-la): "En Germanía vale muchacho y Muchacha. Se llama assimismo la gorrona, o mozuela de mal vivir, desahogada y picara".

En el diccionario de María Moliner se especifica que en germanía significó primero 'chico', pero tiene también un sentido peyorativo como 'bravucón, pincho, rufo, rufián' o 'insolente, presumido, ufano', aunque a veces se emplea sin este sentido peyorativo, como 'atrevido o exento de miedo o servilismo'.

Las definiciones de Marty Caballero aportan ciertos matices: "vulg. El que vive a expensas de una prostituta, sirviéndole de querido privado y de defensor en caso necesario, poniéndola a cubierto de los malos tratamientos y petardos que pudieran darle los que visitan tan impúdica morada" 1 . En general, vemos que hay dos corrientes semánticas para la palabra chulo, una positiva, acentuando la gracia, el donaire, la valentía, el orgullo, la independencia de otros, la ausencia de servilismo; la otra es negativa, y va hasta el extremo que supone la pérdida de mesura, sobrepasando los límites de lo conveniente y cayendo en lo chabacano y rufianesco.

1 Vid. la etimología propuesta para el vocablo rufián. 
Alonso Hernández recoge numerosos textos, que ilustran ampliamente esta semántica, entre ellos los siguientes:

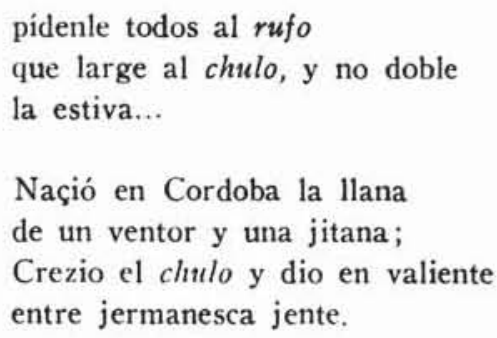

Creo que el étimo de chulo es árabe, a mi entender, la voz $\hat{y} u l l$, pronunciada vulgarmente $* \mathrm{ch} \mathrm{u} 1-10$, lo que justificaria la doble $l$ en italiano, transcrito literalmente en ciullo. Este adjetivo árabe vale 'grande, corpulento y fuerte', que son exactamente las cualidades exigidas para todo aquel que pretenda "chulear" y seguir la "carrera" de matón.

En cuanto a la variante chulamo podria derivarse de $\hat{y} u l a m$ : para este vocablo Kazimirski remite a $z$ ulla $\mathrm{m}$, pero no incluye esta voz en la raiz $z-l-m$; en su forma XI este verbo significa 'ser rápido en sus movimientos', 'ser alto, erguirse y andar con la cabeza alta'; el adjetivo $z$ a li $\mathrm{m}$ vale 'de talla media y bien formado (hombre)' y el participio $m$ u $z$ a ll a $m$ es 'pequeño, ágil y vivo en sus movimientos (hombre)', 'grande y fuerte (caballo)'. El carácter del $\hat{y}$ u $l$ a $m$ no debería diferenciarse mucho del "chulo" .

Algunos textos recogidos por Alonso Hernández parecen dar al chulamo, criado de rufián o de prostituta, un carácter de rufián joven y de poca categoria :

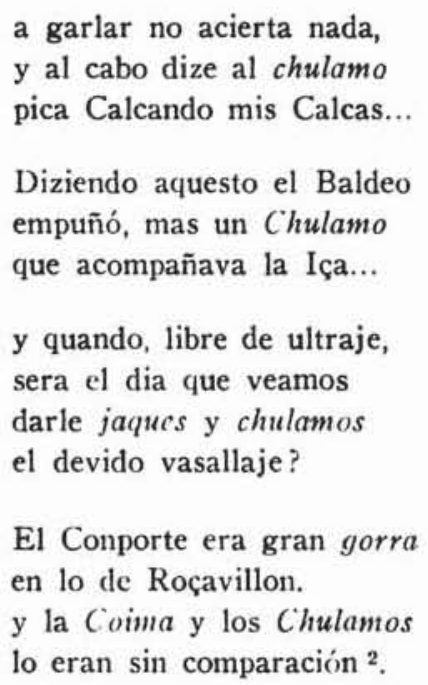

2 Tomados de Hill, Poesias germanescas. Vid. Léxico del marginalismo..., pág. 267. 
En Pedro de Alcalá encontramos traducida la palabra rofián al árabe vulgar granadino por $g a n d \bar{u} r$, étimo del castellano gandul, que pasó con el significado de 'tunante, vagabundo, holgazán', pero que Alcalá traduce también como "garçon assi [que se quiere casar]", "barragán valiente" y "allegado en bando". En las cuatro acepciones que da su Vocabulista se puede resumir todo el proceso semántico de este vocablo: designando, en principio, simplemente a un hombre joven y fuerte; luego toma un sentido peyorativo adecuado a su conducta licenciosa como 'barragán', que Alcalá da como sinónimo de "abarraganado", "adúltero", “combleço" ('rival en amores'), "fornicador", “luxuriosa cosa" y "putañero" (para el femenino añade "fornicaria"); estas cualidades son las que le convierten en un completo "rufián”, el cual, por último, se reúne en bandos para mejor realizar con impunidad sus fechorias. Les estaban prohibidas las armas de fuego por la autoridad, pero ellos se procuraban de tenerlas siempre a la mano.

Había también "rufianes" cobarcles, a quienes se les llamaba "matones de pega", que, como dice Deleito, "explotaban el miedo ajeno para disimular el propio y cotizarle como valentía" ${ }^{3}$; de éstos escribió Lope de Vega:

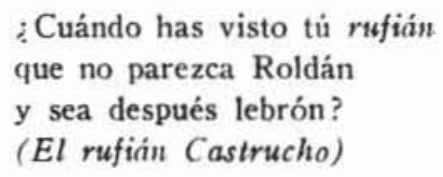

Otra voz empleada como sinónimo, en germanía, es la palabra gayón, de la que Autoridades dice "lo mismo que Rufián"; creo que es vocablo tomado del árabe $g a \bar{a} y y$ o ga $y y \tilde{a} n$, ambas con el mismo significado de 'entregado a sus pasiones; seductor; equivocado, engañado, errado, descarriado', y que luego pasaría a tomar el sentido de 'alegre' y 'vistoso', con el que se extendió a otras lenguas romances.

Las picaras que deseaban encontrar marido, empleaban sus malas artes para hacer valer ante el juez sus demandas contra un caballero a quien hacían responsable de la pérdida de su honra, para lo cual se buscaban testigos falsos que apoyaban sus afirmaciones, y éstos eran generalmente sus propios rufianes. Sobre estos ardides escribe Piñeyro:

Tales escrituras, que hacen las madres sobre las honras de las hijas, me afirmaron ser cosa corriente en Castilla, porque de otro modo fácilmente comprometen a un hombre; y como ellas prueben que gozan de reputación de doncellas y estaban para casar, condenan en casamiento o a dotar en 2 ó 3.000 ducados a cualquier pícara, que a veces son las bellacas más desver-

3 La mala vida.... pág. 126. 
gonzadas, que con dos de sus rufiancs por testigos prueban su buena reputación, y luego meten en prisión y echan por puertas al mejor ${ }^{4}$.

La palabra rufián se documenta ya en los siglos xiv y $\mathrm{xv}, \mathrm{y}$ su semántica se amplia hasta abarcar la calificación suma de la bellaquería y de la infamia, como espadachín de oficio y asesino de alquiler. En La Celestina, dice Areusa :

Vete de mi casa, rufián, bellaco, mentiroso, burlador... (XV).

Los rufianes constituian una verdadera hermandad dentro de la delincuencia y se regian por sus propias leyes, sometidos a unos principios que ellos mismos imponian y juzgaban. Así, se dice en la Vida de don Gregorio Guadaña, de Antonio Enríquez Gómez:

adonde los senadores de las musas jacarandinas se ponian a jugar los pleitos de la vida rufiana... (XI).

También recibía el nombre de rufián, en germanía, el ayudante en la casa de juego cuya misión es proteger a los que hacen pillerías de acuerdo con ellos, en caso de conflicto. En este sentido, recoge Alonso Hernández el siguiente texto:

El segundo interlocutor es el rufián, valiente de esta cuadrilla, está por su cuenta luego que se acaba el juego tomar los naipes porque no vayan a manos ajenas y se conozca la flor y ampáralos con su braveza ${ }^{5}$.

El cuidador de estos antros de juego, que a menudo prestaba con usura a los jugadores, recibía el nombre de coime, con el valor germanesco de 'señor de la casa'; es voz documentada por primera vez, según Corominas, en 1609 (J. Hidalgo), mientras la forma coimero figura ya en 1599 (Guzmán de Alfarache). Autoridades lo define como: "El garitero que tiene a su cuidado el garito o casa de juego pública. Es voz de poco uso". El coime, en principio, no tenía que ser necesariamente un rufián, como lo prueba el texto que se cita a continuación :

Qué dirémos de un desventurado Cóime, que en la casa de juego de que vive, está oyendo continuas blasfemias? 6 .

4 Fastiginia. Cita de Deleito, La mala vida..., pág. 30.

5 Capitulaciones matrimoniales, 56. Vid. en Léxico del marginalismo..., págs. 684-686.

6 P. Juan Martínez de la Parra, Luz de Verdades Cathólicas, part. 2, Plat. 15. 
Eguilaz considera que procede de la palaóra árabe $q \vec{a}^{\prime} i m$, 'el que se encarga de algo, el encargado o gobernante', pero, fonéticamente, creo que sería un étimo más adecuado la voz $q$ a wi $m$, de la misma raíz verbal y de idéntica semántica, como 'jefe, tutor de alguien', así, según se emplee, puede significar 'el marido' o 'el encargado de negocios'. Su significado de 'señor', como 'dueño y tutor', en germanía, queda atestiguado al ser empleado este sustantivo también para nombrar a Dios, que vemos mencionado como "gran coime", "coime de las clareas o del claro", "de las cumbres", "del alto o de lo alto" o "coime prestador de clarea", y la frase "el gran coime que señete en el alto claro", como 'Dios que está en el cielo".

Su femenino daria la palabra coima, de $q a w i m a$, como 'mujer del encargado' o bien 'encargada' ella misma '; Autoridades la define "Lo mismo que gorrona. Es voz de Germanía y usada entre Rufianes", diciendo de la "gorrona" que es "La mugér de baxa fuerte, que sale a prostituir su cuerpo para ganar torpemente su vida" ${ }^{8}$. Hay que tener en cuenta que la sociedad cristiana no admitía como esposas a las mujeres no casadas por la iglesia, aunque ellas se consideraran casadas según sus propios ritos, y por tanto las mujeres que se hallaban en esa situación, aunque fueran honestas, eran consideradas como amancebadas. También se llamaba coima al derecho que se pagaba al garitero por el cuidado de prevenir lo necesario para el juego; en este caso derivaría del diminutivo de $q i m a, q u$ w $a$ y $m a$, que significa 'precio, valor'. Alonso Hernández recoge algunos textos en donde se mencionan :

\author{
Coyma, no estimo en dos chufas \\ a las yças de esta tierra ${ }^{9}$. \\ el Conporte era gran gorra... \\ y la Coyma y los Chulamos \\ lo eran sin comparación ${ }^{10}$.
}

En cuanto a las mujeres, en la lengua de germanía, rufiana era sinónimo de 'alcahueta', y se llamaba asi a la mujer que tiene a cargo una o varias prostitutas a las que dirige, busca clientes y protege; a veces también se daba el caso de ser alcahueta de sí misma, es decir, aquella que busca los clientes

7 Eguílaz da para esta forma, como étimo, el diminutivo g u wa y ma (transcrito cowaimma), 'mujer mundana' ("parva puella" en Freytag), aunque en el apéndice (página 550) lo corrige por ja ymac, transcrito jaima, como "adúltera (mujer)".

8 Sobre las voces gorra y gorrón, puede verse mi trabajo "Revisión a la frase comer de gorra", Boletín de la Asociación Española de Orientalistus, año XIX, Madrid, 1983, págs. 215-243.

- Hill, 30, 12, VIII. Cita de Alonso Hernández, Léxico del marginalismo..., pág. 210.

10 Hill, 57, 217, XXIII. Cita de Alonso Hernández, idem. 
para si. También recibia este nombre la mujer que adiestra putas en la vida que es la suya. Así dice Francisco Delicado, en La lozana andaluza:

Balij. - Y es tanta la libertad que tienen las mujeres, que ellas los buscan y llaman, porque se les rompió el velo de la honestidad, de manera que son putas y rufianas.

Loz. - ¿Y qué quiere decir rufianas?, : Rameras o cosa que lo valga?

Balij.-Alcagüetas, si no lo habšis por enojo.

Loz. - -iCimo! ¿que no hay alcagüetas en esta tierra?

Balij.-Sí hay, mas ellas mismas se lo son las que no tienen madre o tia, o amiga muy amiga, o que no alcanzan para pagar las rufianus, porque las que lo son son muy taimadas... (XX).

vuestra intención es buscar la vida en diversas maneras... Felice Lozana, que no habria putas si no hubiese rufianas que las inxiriesen a las buenas con las malas... (XLII).

que voto a Dios, con putas y rufianas y tabaqueras no podemos medrar (XXXVII).

Con la palabra rufián se identifican otras formas, como las voces rudio o rufo, también rufista, sobre cuya etimología se apoyan algunos autores para encontrar un étimo adecuado para la primera, ya que su semántica es tan afín como su fonética, puesto que designa igualmente al hombre de mal vivir, chulo protector de prostitutas a costa de las cuales vive. Alonso Hernández cita algunos textos muy significativos ${ }^{11}$ :

Quiso Lugo empinarse sobre el hombre y, siendo rufo de primera tonsura... (El rufián dichoso, I).

y, aunque puesto de rodillas le hizo suplicaciones, el rufo le hizo barquillo en el agua... (La picara Justina, I, II).

Yo vos ternia bien contento,

si diessedes escarmiento

al rufo que me ha garlado (Hill, 3, 15, I) ${ }^{12}$.

y volví a la posada, donde hallé a la señora, y al rufo, y al escribano (Marcos de Obregón, III, IX).

11 Vid. nota 3.

12 John M. Hill, Poesias gcrmanescas. 


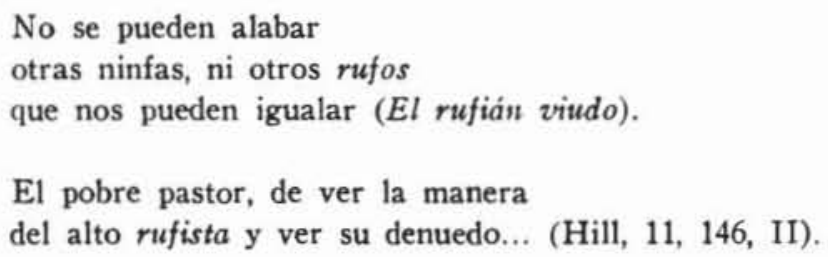

En el Diccionario de Autoridades se cita el siguiente texto de un romance de germanía:

$$
\begin{aligned}
& \text { En el compás los atajan, } \\
& \text { los que en amistades tercian, } \\
& \text { que son los rufos godeños, } \\
& \text { a quien los demás respetan. }
\end{aligned}
$$

La localización de las zonas donde más destacaba esta vida rufianesca parece resumirse en el refrán español que cita Bartolomé Joly, limosnero del rey de Francia, que vino a España en 1603 e hizo luego el relato de su viaje, el cual dice: "Rufián cordobés y p... valenciana" ${ }^{13}$.

Como dice Julián San Valero Aparisi, "en todas las Españas se dio el picaro, pero sus mejores escenarios fueron Madrid y Sevilla", para añadir después, "escenario máximo de toda picardia, en Madrid, Corte de los Milagros, competian indigenas y extranjeros en nutrir también el hampa de la mala vida... todos concurrían a los bodegones, tabernas, posadas, garitos, ventorrillos y mancebias...". Todo lo cual concuerda con el étimo que consideramos adecuado para hampa, el árabe ${ }^{c} a n b a$, 'beber vino'. En cuanto a Sevilla, afirma que "picaros, tahures y rufianes del mundo entero deambulaban por El Arenal, que era el meollo de la mala vida sevillana" ${ }^{14}$. En el siglo xvir, escribía el racionero de la Catedral de Sevilla, Porras de la Cámara, al cardenal Niño de Guevara: "Lo que más en Sevilla hay son forzantes, amancebados, testigos falsos, jugadores, rufianes, asesinos, logreros..., vagabundos que viven del milagro de Mahoma, sólo de lo que juegan y roban... Está Sevilla menos segura y más sospechosa que Sierra Morena y $\tan$ miserable y destrozada como Jerusalén en la cautividad del Egipto" ${ }^{15}$.

Sobre todo eran destacadamente abundantes en Andalucía, especialmente en Córdoba, siguiendo después en preferencias Sevilla; las sevillanas continuaron observando la costumbre morisca de ir a las casas de baños públicos, y el mismo Cervantes dice en El celoso extremeño: "Hay en Sevilla un género de gente ociosa y holgazana, a quien comínmente suelen llamar gentc

18 Cita de Deleito, La mala vida..., pág. 55.

14 Vid. el prólogo de La mala vida..., de Deleito, pág. 11.

15 Cita de Deleito, La mala rida..., págs. 169-170. 
de barrio"; también Granada, Málaga, Zahara y Sanlúcar, donde indudablemente tenian asentados sus reales.

Corominas y Pascual indican que la palabra rufián es vocablo común a todos los romances de occidente, muy antiguo en Italia y el sur de Francia, y quizás nacido en el primero de estos paises, aunque consideran que es de origen incierto, tal vez procedente del latín $r \bar{u} f u s$, 'pelirrojo'.

Habitualmente se consideran las voces rufo y rufián como dos variantes de un mismo étimo, bajo la sugerencia de un origen latino, sin embargo, según Corominas, parece demostrado que rufo, 'rufián', no se extrajo de este vocablo, sino que fue vieja palabra indigena, documentada ya hacia el aก̃o $1500^{11}$.

Yo creo que rufo procede del árabe $r u j w$ (similar a $r a j w$ y $r i j w$ ), que significa 'flojo, blando, flácido, relajado, acomodaticio, condescendiente, dejado, ahandonado, perezoso, indolente, negligente, haragán, holgazán, gandul'. El sonido de la $j \bar{a}^{\prime}$ equivalía al sonido de la $h$ aspirada, la cual, por ultracorrección, solia interpretarse como $f$, por lo que de *ruhu se escribiría ${ }^{*} r u f u^{17}$.

En cuanto a rufián, pienso que su étimo adecuado sería el árabe $r u^{c} y \bar{a} n$, forma característica de los nombres que designan al macho de una especie y también plural del participio $r \bar{a}^{c i n}$; esta palabra significa 'pastor, gobernante, patrón' es decir, 'todo aquel que cuida o vela sobre algo, que lo guarda y vigila'. Esta era, según hemos visto en los textos, la labor del rufián, que se contrataba como esbirro para servir de guarda personal de quien lo requería: garitos, burcleles, prostitutas, e incluso damas o caballeros con problemas personales, los cuales se valían de estos matones a sueldo para realizar sus venganzas personales y sus ajustes de cuentas, al margen de la justicia. Teniendo en cuenta que el cayn, sin sonido equivalente en las lenguas romances, solia sustituirse por la $h$ aspirada, con lo cual tendríamos la misma evolución fonética de la palabra anterior, es decir *ruhyán y *rufyán.

En la práctica, dentro de la vida rufianesca, ambos conceptos se confundian en la germanía, pero esto ocurría también ya en la lengua árabe, pues

16 En cuanto al verbo arrufar $(-s c)$, ya hice anteriormente un estudio sobre su etimología, proponiendo su derivación del verbo árabe $r a f u^{c} a$, 'estar levantado, elevado; ser alto, ilustre', o $\operatorname{raf} a^{\prime} a$, 'levantar, alzar, subir, exaltar', probablemente partiendo del nombre de acción $a r-r u f \bar{u}^{c}$, que dio el castellano arrufo, empleado en náutica para expresar la curvatura del buque en sentido de la eslora, levantándose más por la proa y la popa que por el centro. $V$ id. "Aportaciones árabes en el arte de navegar: voces náuticas de origen árabe”, Cuadernos de estudios medievales, XIV-XV, Universidad de Granada, 1985-1987, págs. 75-95, en pág. 77.

17 Son innumerables las muestras que pueden citarse de esta evolución fonética, por ejemplo: azofra de as-sujra, rahez y rafez de $r a j i s .$, zalea, azaleja (Andalucía), zalefa (Sevilla), salefa (Valencia), de sali $j a$, etc. 
Lane da como sinónimas las raices de donde derivan, $r a j \bar{a}$ y $r a$ " $\bar{a}$, junto con otras dos muy interesantes, que son hašs $a$ y läna, todas con el significado común de 'ser blando, ceder, ser servicial'; así encontramos el sustantivo la yn como 'flojo, suave, manejable', lo mismo que $r u j w$. Pues bien, en Alfonso de Palencia volvemos a encontrar unidas semejantes voces cuando dice: "Leno... es el rufián o alcaguete enseñoreado a las mundarias y el que las engaña: dicese leno porque primero las halaga con blandas palabras a las mesquinas para que sean burdeleras" (240b); y también dice: "abenidor" (10b) y "Agapeta es rufián que desonestamente conversa con las fembras y es nombre de priapo" (10d).

Lè n ō es palabra latina antigua que significa 'alcahuete', de donde se tomó después, en el siglo xvIII, el culterano lenocinio, y $l \bar{e} n i s$ equivale a 'dulce, suave al tacto'; la coincidencia semántica se repite. Ernout y Meillet afirman que son voces antiguas en latín, clásicas, usuales, pero sobre todo populares, considerando que $1 \bar{e}$ n õ es, sin duda, un préstamo de otra lengua. Es posible que en latin tuviese ya un origen semítico, si lo comparamos con el árabe la $y n$, 'suave, blando, dulce, flojo, manejable', cuya derivación normal sería *lēn.

En cuanto a la otra variante rudio, que aparece indistintamente con las anteriores, creo que procede también del árabe $r u d$ ' (o $r i d$ '), 'ayuda, apoyo; ayudante, auxiliar; valedor', o más probablemente del adjetivo de cualidad de la nisma raiz verbal $r a d i^{\prime}$ (o $r u d i^{\prime}$ ), pues el verbo $r a d u^{\prime} a$ significa 'ser malo, depravado $y$ abyecto'.

En el estudio de José Luis Alonso Hernández, que titula El lenguaje de los maleantes españoles en los siglos XVI y XVII: La Germania, es sumamente interesante el apartado que dedica a la "Jerarquización de la Valentónica”, cuyo núcleo central es el rufián-valentón; describe en él este autor el proceso de las diversas fases por las que ha de pasar el aspirante a seguir esta "carrera" de la delincuencia profesional. Muchos de los nombres que va a recibir, en cada una de las etapas que ha de superar, están enraizados en la lengua árabe.

Parece ser que la cualidad indispensable para iniciar el ingreso en estos cursos era la calidad de chulo (chulamo o chulillo), calificativo que generalmente se conservaba hasta llegar al doctorado: la iniciación se hacia, como aprendiz, con la categoría de mandil, cuya denominación procede del árabe ma nd i l (trainel, pagote o mandilete), tomado quizás no tanto de la prenda de este nombre, a modo de delantal, cuanto por su oficio de recadero entre rufianes y prostitutas, puesto que $m a n d i l$ es el nombre de instrumento del verbo n a d a la, 'transportar de un lado a otro', según puede verse en los siguientes versos del Romancero General: 
Al mandil llaman trainel,

porque lleva y trae recados... 18 .

De aquí se pasaba a la categoría de rufián (rudio, pendencia, gancho ...), y de rufián se ascendia posteriormente a la posición de jaque (bravo, valentón, valiente). Esta categoría se completaba en la de jaque-rufián (algo asi como teniente-coronel de estas milicias), el cual recibía también los nombres de germano, matón y guapo, a más de algún otro.

El grado máximo del personal en activo era el de jayán, también llamado cherinol. Yo creo, como Eguílaz, que jayán viene del árabe y que su étimo es la palabra h a y y ã $n$, 'vivo, animoso, fuerte', pero que este étimo sólo sería adecuado al castellano para la acepción como 'persona de gran estatura, robusta y de muchas fuerzas'. En este sentido se empleaba también para las mujeres, del mismo modo que en Andalucia se las tilda de jaquetonas; así se dice en el tranco VII de El Diablo Cojuelo: "y en un balcón grande de la fachada va la Esperanza: una jayana vestida de verde, muy larga de estatura, y muchos pretendientes por abajo...".

Pero, sin embargo, el sentido que en castellano se clio a este vocablo como 'rufián y matón', está más próximo de la voz árabe j a y y ān, 'traidor' 19, que expresa la profesionalidad del $j \bar{a}^{\prime} i n$, 'el que es malo, ruin, perverso, malvado, merodeador, bandido' y al que Pedro de Alcalá traduce por "maldadoso". Podrían incluirse en este nombre de oficio todas las acepciones del verbo $j \bar{a} n a$ : 'traicionar, engañar, ahandonar, violar, romper, fallar, perjudicar; ser infiel, ser perjuro, delator, malversador: infestar las rutas y cometer bandidaje; rolar': el sustantivo jawäna es 'fullería, trampa en el juego, trapaceria'. En la semántica de esta raíz $j-w-n$ se encuentra concentrada toda la gama de actuaciones que eran propias de un auténtico jayán, jefe máximo en activo de la valentónica germanesca, a quien todos respetaban, y que al julilarse podía aspirar a ser miembro del Trono Subido o consejo supremo.

Nuestra literatura del Siglo de Oro se vio seducida, a veces, por este mundo aparte de la picaresca, que disponia de un léxico absolutamente peculiar; como dice Deleito, "la chusma del hampa usaba una jerga especial, que se llamaba de germanía por extensión: por aplicarse esta palabra, que significa hermandad, a la asociación de picaros, hermanos o germanos, que formaban un grupo aparte de la sociedad corriente. Usaban aquel lenguaje para su seguridad, como forma de entenderse entre si, sin que los profanos penetrasen el sentido de sus palabras" ${ }^{20}$.

\footnotetext{
$18 V i d$. en Alonso Hernández, El lenguaje de los maleantes, pág. 96.

19 Vid. Dozy, Supplément, I, 414.

20 Vid. La mala vida en la época de Felipe IV. pág. 113.
} 
A este lenguaje de germania se le llamaba también jacarandina, jerigonza y algarabia, del árabe $a l$ - 'arabiyya, 'la lengua arábiga', lo que hace suponer que entre estas gentes militaban muchos arabófonos todavia ${ }^{21}$; esto, unido a la abundancia de apodos o "alias" y de patronímicos, tan característicos en la onomástica árabe, que se encuentran entre los nombres de personajes que se hicieron célebres en la picaresca española, apoyan el convencimiento de que la aportación prestada por los moriscos en este estrato social debe de ser tenida en cuenta.

$\mathrm{Si}$ investigamos profundamente sobre el origen de las palabras de esta lengua peculiar, vemos que muchas de ellas son fácilmente reconocibles en el vocabulario árabe, según podremos ir comprolando. Por ejemplo, entre los nombres que recilian las mujeres de vida pública, rameras que convivian en este ambiente del "hampa", se citan algunas que nos resultan insólitas en la lengua castellana, como: iza o más antiguo $y \zeta a$, que creo se corresponde con la voz "ässa (en árabe granadino, por la imāla convertido en ' $i s s a$ ), 'la que ronda o busca de noche'. rabiza, probablemente de $r a b \bar{i} s a$, 'la que acecha, está apostada, aguarda o espera a alguien' ${ }^{22}$; gaya, quizás de $g \bar{a}-$ y ya, 'seductora; la que descarría, pierde o extravía', voz que pasaria también a Francia ${ }^{23}$; podrian citarse otras muchas calificaciones, algunas de étimos oscuros, como marquida, marquisa o marquiza ${ }^{24}$, sinónimos también de coima, maraña ${ }^{25}$, pencuria, hurgamandera ${ }^{28}$, chula y chulama, bizmaca ${ }^{2 \pi}$, golfa, yodeña (las de más alcurnia y que ganaban más), dama de achaque,

21 Vid. Alonso Hernández, El lenguaje de los malcantes..., pág. 9.

22 También podría interpretarse como derivado de $r a b i \underline{d} a$, 'ágil, ligera', o $r a b i d a$, 'la que se echa o recuesta o se alberga con alguien'; todos estos vocablos, con sentido más o menos equivoco, podian producir en castellano, fonéticamente, la palabra rabiza.

${ }^{23}$ Autoridades dice que significa, en Germanía, "muger pública" y la voz gayón es "lo mismo que Rufián".

24 Podia ser corrupción vulgar de $m u r q i d, a$, 'la que hace acostarse o yacer, dormir y cohabitar con ella' ( $V i d$, en Alcalá "dormideras preparadas", donde dice "marqad" por murqid, igualándolo a "dormitorio lugar", marqad; dentro de esta raíz incluye la voz $r u q \boldsymbol{d} d$, como 'jazija', 'yacija', empleada también en la locución "acostamiento de mujer") o de murqisa, 'la que hace bailar o galopar'.

25 Quizás por muraccina, 'la que es necia y casquivana'.

2n Debe ser la variante femenina de "hurga mandeles", criados de rufianes y de mujeres públicas.

${ }_{27}$ Alonso Hernández considera que se refería probablemente a una ramera de baja calidad debido a la edad y que tendría probablemente necesidad de aplicarse bizmas, constituídas, según Covarrubias, por "cierto emplasto que aprieta a la parte del cuerpo o miembro donde se aplica", considerando su posible origen del árabe; es posible que su étimo sea la palabra bizma, como 'mordiente'. Este se componía de retama, jara, manrubio y piña, y servía, según palabras de Alonso Hernández, "para reducir el coño de las prostitutas que lo tenían dilatado por el prolongado uso. A veces servía para fingir el virgo de las más jóvenes que querian pasar por vírgenes varias veces". Vid. Léxico del marginalismo..., pág. 55, "apretaduras". 
tusona (dama del tusón, por toisón), cantonera... Según Bonnecase, en el siglo Xvir habia en la Corte de Madrid unas 300.000 mujeres públicas ${ }^{28}$. El francés Brunel, refiriéndose a Madrid, decia:

No hay ciudad en el mundo donde se vean más meretrices a todas horas del dia. Las calles y los paseos están llenos. Van con velos negros, y los repliegan sobre el rostro, no dejando sino un ojo al descubierto. Hablan de modo atrevido a la gente, mostrándose tan impúdicas como disolutas... Estas pecadoras campan con entera libertad por Madrid, porque las grandes damas $y$ las mujeres de bien no salen apenas ${ }^{29}$.

A los burdeles se les llamaba también manflas $^{30}$ y piflas $^{31}$. Sería necesario hacer un estudio muy detenido y profundo sobre este singular vocabulario, en donde hay un verdadero derroche de matices:

Virlos, jaques y mandiles,

coimas, marquizas, chulamas... ${ }^{32}$

También sus costumbres sociales eran muy peculiares. Las bodas solian realizarse al margen de la iglesia, a la que llamaban altana o antana, y así llamaban altanarse, según palabras de Alonso Hernández, al hecho de "casarse a la manera de los rufos y putas, es decir, ponerse un hombre y una mujer de acuerdo para vivir juntos y repartir las ganancias que del oficio de la mujer se deducen" ss.

A partir de El Lazarillo de Tormes, a los pícaros valentones, que desafiaban y perseguían a cualquiera, también se les denominó jacos, jácaros, jacarandos y jacarandinos. Se hizo, incluso, una poesía rufianesca, a la que se le dio el nombre de jácara, del árabe $\hat{y} a k$ k a ra, 'hacer rabiar, molestar a alguno'. Esta palabra designaba un tipo de romance alegre en que por lo regular se cuentan hechos de la vida airada, y, en lenguaje de germanía, según palabras de Cotarelo Mori, "se aplicó en un principio a designar el conjunto de jaques, rufianes o pícaros, su vida y sus costumbres, o lo que es igual, a la picaresca; pero en lo que tenía de más alegre, ruidoso y menos crimi-

28 Relation de l'Etat et goubernement d'Espagne. Cita de Deleito, La mala vida..., pág. 45.

29 Voyage d'Espagne. Cita de Deleito, idem, págs. 44-45.

so Este nombre es probable que proceda del árabe manfila, 'lugar de regalo y donde se cede a los soldados el botín'.

s1 Quizás por pilfa; en Germanía pilfar es espolear al caballo para que ande. Vid. Alonso Hernández, Léxico del marginalismo..., pág. 616.

32 Hill, 45, 140, XIV. Cita de Alonso Hernández, Léxico del marginalismo..., pág. 210, en coima.

ss Vid. nota ant., pág. 32. 
nal" ${ }^{34} ;$ y jacarandina, según expresión de Salillas, "quiere decir junta o reunión de pícaros, lenguaje de pícaros, engaño de pícaros y música de pícaros" 35 .

Como muestra de este léxico de la picaresca, podemos leer en la jácara de Quevedo, que titula "Carta de Escarramán a la Méndez", frases como éstas :

Ya está guardando en la trena ${ }^{36}$ tu querido Escarramán, que unos alfileres vivos me prendieron sin pensar.

Prendiéronme en la bayuca ${ }^{3 i}$, entrándome a remojar cierta pendencia mosquito que se ahogó en vino y pan.

Como el ánima del sastre suelen los diablos llevar, iba en poder de la gura ${ }^{38}$ tu desdichado jayán.

A la Pava del cercado, la Quirinos y Cerdán, a la Escobedo y la Téllez, a la Rocha y la Guzmán,

a Mama, y a Taita ${ }^{39}$ el viejo, que en la guarda vuestra están, y a toda la gurullada 40 , mis encomiendas darás.

Fecha en Sevilla, a las once de este mes que corre ya. $\mathrm{El}$ menor de tus rufianes y el mayor de los de acá ${ }^{41}$.

34 Vid. Introducción a la Colección de Entremeses, Loas, Bailes, Jácaras y Mojigangas desde fines del siglo XVI a mediados del XVIII (tomo XVII de la Nueva Biblioteca de Autores Españoles, apartado IV: Jácaras, pág. CCLXXIV).

35 El delincuente español, 1898, tomo El hampa, pág. 77.

36 En germanía, 'trenza, soga; cárcel'.

s7 También "bayunca", en germanía, 'taberna'.

38 En germanía, 'justicia' y en plural 'galeras', pues designaba el 'castigo de galeras'; probablemente abreviatura de gurapas, nombre que se daba a las galeras a las que se condenaba a los delincuentes, que a su vez procede del árabe $g u r a d$, 'navío, galera'.

30 Nombre con que, en algunos sitios, llaman los niños al 'padre' y también 'rufián (hombre que trafica con mujeres públicas)'.

40 Equivale a 'corchete' o 'justicia', 'tropa de corchetes y alguaciles' y también 'tropel de gente de cualquier especie'.

41 Poesía, Ed. Ebro, Zaragoza, págs. 120-123. 
Escarramán fue un famoso jaque sevillano, que vivió en los principios del siglo xvir, según lo afirma Cervantes en su entremés El rufián viudo, y sus hazañas se cantaban ya en los romances populares.

La plana mayor de la Germania, formada por los jubilados distinguidos, era el llamado Trono Subido y también Padres de la Jerigonza o Padres de la Facultad Matante, Tercio de la Liga, etc.

Pfandl hace un resumen de los oficios menudos de los picaros: "Fauna abigarrada en encrucijadas y callejones, formada por mendigos, caldereros, pregoneros, mozos de mulas..., traficantes, buhoneros, inválidos, vendedores, arrieros y titiriteros, músicos ambulantes y prestidigitadores; las más infimas y menos decorosas profesiones, como las de taberneros, cortadores, figoneros, esbirros y verdugos; y..., la gente maleante de toda suerte y condición, como los rufianes, alcahuetes, fulleros, bandidos y salteadores ..." 42 . Pues, como se dice en El coloquio de los perros, "esto del ganar de comer holgando tiene muchos aficionados y golosos".

La gente del "hampa" constituia un mundo aparte dentro de la sociedad, un mundo reconocido y admitido como normal, aunque las fronteras que lo delimitaban eran fácilmente transgredidas, pues muchos hijos de buenas familias se pasaban a esta vida desenfadada e irresponsable, atraídos por el deseo de aventura y libertad, tanto física como moral, pero hay una gran diferencia entre el picaro y el rufián: el primero "no tenia malos instintos, no era perverso, sólo cínico y amoral. Si robaba, era lo indispensable para comer, y más que el robo propiamente tal, practicaba el hurto. El rufián, al revés, era perdonavidas, ladrón de profesión y a veces asesino" ${ }^{43}$.

\section{BiBLIOGRAFÍA}

Alcalí, Fr. Pedro: Vocabulista arauigo en letra castellana, Granada, 1505.

Alonso Herníndez, José Luis: El lenguaje de los maleantes españoles de los siglos XVI y XVII: La Germania (Introducción al léxico del marginalismo), Ediciones de la Universidad de Salamanca, 1979

- Léxico del marginalismo del Siglo de Oro, Universidad de Salamanca, 1977.

Deleito y Piñuela, José: La mala vida en la España de Felipe IV, Madrid, Alianza Editorial, 1987.

Diccionario de Autoridades: Real Academia Española, Madrid, 1726; ed. facsímil, Madrid, Ed. Gredos, 1976.

Dozy, Reinhart: Supplément aux dictionnaires arabes, Ed. E. J. Brill, Leyde: Paris, G. P. Maisonneuve et Larose, 1967, 3. a ed.

Eguflaz y Yanguas, Leopoldo de: Glosario etimológico de las palabras españolas de origen oriental, Granada, 1886.

42 Introducción al estudio del siglo de oro. Cita de Deleito, idem, 128-129.

4 Vid. La mala vida..., pág. 123. 
ERnout, A. y MeIllet, A.: Dictionnaire étymologique de la langue latine. Histoire des mots, Paris, Ed. Klincksieck, 1979, $4 .^{\mathrm{a}}$ ed.

Kazimirski, A. de Biberstein: Dictionnaire arabe-français, Paris, Ed. Maisonneuve, 1860.

LANE, Edward William: An arabic-english lexicon, Beirut, Librairie du Liban, 1968.

Marty Caballero, D. E.: Diccionario de la lengua castellana, Madrid, Casa Ed. Vda. de Rodríguez 1883.

Moliner, María: Diccionario de uso del español, Madrid, Ed. Gredos, 1980.

Palencia, Alfonso de: Universal vocabulario en latín y en Romance, Sevilla, 1490.

Pezzi, Elena : El vocabulario de Pedro de Alcalá, Almería, Ed. Cajal, 1989. 